\title{
Materials Science: Parepistemes Rampant
}

\section{Robert W. Cahn}

This article is based on a plenary address which Robert W. Cahn, Cambridge University, delivered at the International Union of Materials Research Societies International Conference on Advanced Materials (IUMRS-ICAM'99) hosted by the Chinese Materials Research Society (C-MRS) in Beijing, on June 14, 1999. A version of this article is also being published in Materials Today, the quarterly magazine published by Elsevier for the European-MRS. A report of the IUMRS-ICAM'99 meeting will be published in a future issue of MRS Bulletin.

Disciplines emerge either by the fission or the fusion of older disciplines. The reason for such emergence may be profound or else trivial. Fission is the more common: thus, physical chemistry was created and split resolutely from organic chemistry in the 1880 s because of the founders' passion to establish generalizations about reaction equilibria and kinetics as distinct from collecting facts about particular reactions. That was a profound event. Chemical physics split from physical chemistry in the 1930s mainly because of many people's exasperation with a physical chemist who was also a particularly troublesome journal editor; practitioners still have great difficulty in pinpointing the difference between physical chemistry and chemical physics. That was a trivial event. Colloid scientists have made repeated attempts to split away from physical chemistry on the basis of their focus on tiny particles, but the split has never firmly taken hold.

The field of materials science and engineering, MSE, is different. It came into being by the fusion of metallurgy and solid-state physics, much later complemented by the infusion of materials chemistry and even, to a limited extent, chemical engineering. Solid-state physics is itself a relatively recent concept: It was not really recognized as a discipline before the feats of physicists like Frederick Seitz, Nevill Mott, William Hume-Rothery, and Rudolf Peierls, some still living and some only recently dead. (Hume-Rothery was in fact a chemist, with a PhD degree in metallurgy, who positioned himself in the undefined area between physics, physical chemistry, and metallurgy and did more to bring them closer than anyone else except Seitz.) Metallurgy itself, as a proper science as distinct from a craft, scarcely goes back before the middle of the 19th century. The fusion of metallurgy and solid-state physics came about because of perceived educational needs in the late 1950s, and that fusion was cemented by the invention of the Materials Research Laboratories in the United States in the 1960s. The rearguard fight of those who did not want to be fused was long and bitter; great research metallurgists such as Robert Mehl fought hard against these developments but they were defeated in the end. Others, in the first half of the 20th century, poured comprehensive scorn on the whole enterprise of scientific metallurgy: Thus the British inventor of stainless steel, Harry Brearley, who was an excellent practitioner but had no scientific education, as late as the 1930 s wrote, "To know the ingredients of a rice pudding and the appearance of a rice pudding when well made does not mean, dear reader, that you are able to make one." That deeply entrenched conviction (and all that flowed from it) was one which materials scientists had to combat for many decades.

Solid-state physics was in its nature much more quantitative than was metallurgy in the middle of the 20th century. From 1935 to 1955 , approximately, a "quantitative revolution" occurred in the borderlands of the two sciences, including for example the elastic theory of dislocation

Material Matters is a forum for expressing personal points of view on issues of interest to the materials community. behavior (explanation of discontinuous yield and strain-aging in steels), randomwalk theory applied to diffusion and later also to rubberlike elasticity, band theory of conduction in solids, cohesion of solids viewed in quantum-mechanical terms, and theory of color centers in ionic crystals.

It is instructive to consider the attitudes of metallurgists and physicists to dislocations. Many metallurgists were fiercely resistant; they thought the dislocation, postulated in 1934, an unnecessary hypothesis-and it was a hypothesis only, since its reality was not demonstrated until the end of the $1940 \mathrm{~s}$. Among physicists there were positivists, like Percy Bridgman, who did not take an interest in dislocations. Most in both camps, however, were convinced by the rigorous quantitative treatment, especially by Alan Cottrell. A particularly convincing example of the power of the strictly quantitative approach was J.L. Snoek's linkage, 1939-1941, of internal friction in wires of iron containing dissolved carbon or nitrogen to the solute concentration. That linkage allowed minute interstitial concentrations to be measured by purely physical means. This marked the beginning of this century's conversion of compositional analysis of materials from a chemical into a physical skill.

I have just used the
word parepisteme, which
I have invented to denote a
self-contained subsidiary
field of research.

In addition to the vital quantitative approach, one other factor brought widespread acceptance of novel concepts like dislocations and Guinier-Preston zones. This was an emphasis on visual demonstration: Seeing is believing. Earlier in the century, the invention by Charles (C.T.R.) Wilson in Cambridge University of the cloud chamber, side by side with the micrographic demonstration and measurement of Brownian motion, had dispelled the last doubts of the anti-atomists, apart from a very few irreconcilable diehards. In the 1950s, the developments of improved methods of optical microscopy (e.g., decoration, etching, and infrared microscopy) led to a proper demonstration of the geometry of dislocations. The real visual breakthrough came from the introduction of transmission and scanning electron microscopies in the mid-1950s. This, together with the crucial invention of electron microprobe analysis (the most important postwar instrumental invention, originally 
made by Raimond Castaing in France), transformed the power of the new integrated science of MSE. The new instruments, jointly with new theories that were fed by them, led to dramatic advances in the understanding of phase transformations, the factors governing microstructure and its quantitative characterization (stereology), and the identification of property changes due to trace elements.

Much more recently, chemists have begun to accelerate their infiltration into MSE. "Materials chemistry" has become a recognized concept and various new journals include the term in their titles, whereas "materials physics" is not used in journal titles (although one journal is entitled Applied Physics A-Materials Science and Processing, and edited by someone working in an institute for biophysical chemistry). Materials chemists have wrought remarkable developments in processing, a broad aspect of MSE which was identified by the U.S. Academies, a few years ago, as one requiring concentrated attention. Techniques such as self-sustaining hightemperature synthesis, and sol-gel procedures (and, more generally, what French chemists have dubbed chimie douce, soft chemistry) are examples. More recently, techniques for self-organizing periodic microstructures have been perfected by materials chemists such as George Whitesides at Harvard University; this field is regarded as so important that a new materials encyclopedia currently in preparation has an editor solely responsible for articles on "self-assembling materials chemistry." The curious new parepisteme of "supramolecular chemistry"-the spontaneous self-arrangement of groups of large molecules-is closely related to self-assembling materials chemistry.

I have just used the word parepisteme, which I have invented to denote a selfcontained subsidiary field of research. The term derives from the Greek "episteme," a field of knowledge, and "para-," here meaning "subsidiary." Many of the hundreds of parepistemes attached to MSE are fields of research which were not, initially, directed to the solution of any practical problem (e.g., diffusion in solids; highpressure research; the vast domain of crystallography, including but not restricted to crystal-structure determination; microstructural coarsening [Ostwald ripening]; and piezoelectric behavior). Sometimes, a parepisteme has grown indirectly out of an attempt to solve a practical problem; thus, the preparation of metallic single crystals for research purposes emerged, paradoxically, from steel metallurgists' attempts, early in the 20th century, to avoid the generation of large grains in steel objects.
However, once it accidentally became clear how to make large crystals, especially of iron, they were used for fundamental research on metal plasticity, and incidentally led to the perfection of a crystal growth method which was later used to grow silicon crystals for microelectronics. Other parepistemes, very detailed and subtle, did grow directly from urgent practical needs: The study of radiation damage in nuclear fuels is a prime example, while deformation maps constitute another.

The field of materials
science and engineering
came into being by the
fusion of metallurgy and
solid-state physics.

In my view, the birth and flowering of parepistemes is one of the key progenitors of modern MSE, and they are vital to its further development because several parepistemes are integrated in the solution of clearly defined, difficult practical problems, such as Greg Olson's approach to the first-principles design of high-strength steels. The present stage of development of MSE is characterized by the prevalence of review papers and entire books devoted to a single parepisteme. This could not have happened a century ago.

As MSE became ever more quantitative and less handwaving in its approach, one feature became steadily more central: the power of surprise. Scientists learned to recognize when they had observed something mystifying - that is, surprising-or when an observation was wildly at variance with the relevant theory. The importance of this "surprise factor" goes back to Louis Pasteur, who defined the origin of scientific creativity as being "savoir s'étonner à propos" (to know when to be astonished). He applied this principle first as a young man to his precocious observations on optical rotation of the plane of polarization by certain transparent crystals. A contemporary corollary of Pasteur's principle was, and remains, "accident favors the prepared mind." Because the feature that occasions surprise is so unexpected, scientists who have drawn the unavoidable conclusion often have a sustained fight on their hands. A few exemplifications are provided in outline form and in chronological sequence:

- Ernest Rutherford and the structure of the atom in which he found that a very few of the alpha particles used to bombard a metal foil came straight back toward the source, as he later commented, "It was about as credible as if you had fired a 15inch shell at a piece of tissue paper and it came back and hit you." The point was that the observation was wholly incompatible with the then-current "currant-bun" model of the atom. This quotation has always seemed to me the perfect illustration of Pasteur's principle.

- Pierre Weiss and the recognition that the only way to interpret the phenomenon of ferromagnetism was to postulate the existence of magnetic domains, which were only demonstrated visually many years later.

- A.A. Griffith and the need to postulate the existence of invisible microcracks in the surfaces of brittle materials in order to account for their low resistance to fracture. - Hermann Staudinger and his insistence, against resolute opposition, on the reality of covalently bonded macromolecules of variable molecular weights. This presumption was extremely surprising at the time because of the variable molecular weights, but inescapable.

- Egon Orowan, Geoffrey Taylor, and Michael Polanyi and their joint invention of the dislocation to explain the weak resistance to plastic deformation in various crystals. Again, invention was followed by demonstration only many years later.

- Albert Bradley and Abe Taylor in the 1930 s and the recognition of a large concentration of structural vacancies in an intermetallic compound. This insight is the object of renewed skepticism at present.

- Charles Frank and the recognition that crystal growth at small supersaturations required the participation of screw dislocations. Here, visual proof came instantly. - Andrew Keller and the necessity of assuming chain-folding in the formation of polymer crystals, although it took many years for this notion to be accepted. He was vehemently challenged at first.

In these examples of Pasteur's principle in action, surprise was occasioned by a mismatch between the initial theory and the results of measurement. This kind of mismatch, combined with Pasteur's principle, was and remains a powerful incentive to intellectual innovation in MSE, and the kind of discovery based on this principle only became possible once the quantitative approach had become habitual in MSE. In this respect, Griffith's prediction of microcracks in the early 1920s was distinctly precocious. It may well be that the most significant conceptual innovations arising from such mismatches have mostly been made, and that this mode of advance in MSE may henceforth be subject to the law of diminishing returns.

I come now to the most striking of all changes in the practice of MSE, which will certainly have a major impact on the 
future of our science. This is computer simulation. The first stirrings of this approach, in the form of the Monte Carlo method, came just after the Second World War, at Los Alamos, and it was applied to neutron physics. This development owed everything to pure mathematicians like Stanislaw Ulam (his little daughter complained at the time that her father spent all his time thinking instead of playing with her): Their involvement led to a prolonged, abstruse debate whether a table of truly random numbers can ever be generated. The origins of Monte Carlo simulations and the difficult problems which had to be solved en route have been memorably surveyed by the Harvard science historian Peter Galison in his book, Image and Logic (University of Chicago Press, Chicago, 1997). At one point, Galison quotes an early practitioner asking, "How should one class this type of data-to-model simulation? As experimental theory? Theoretical experiment? Is it a case of induction from data? Deduction from theory?" Galison continues, "Each such attempt to force the argument back into older categories strikes me as awkward, a rearguard action unable to capture the novelty of procedure...I would suggest that the Monte Carlo method is best seen as expanding the spectrum of persuasive evidence, a tertium quid."

As the power and speed of computers improved and as practitioners enhanced the subtlety of their programming methods, the range of issues treated by Monte Carlo and molecular dynamics "experiments" increased apace. In retrospect, the choice of themes to be examined by these methods sometimes seems odd; for instance, for decades computer simulation was applied to the process of grain growth during the annealing of polycrystalline metals. That process is not particularly important in itself, but it is perfectly adapted for comparing the validity of competing simulation strategies. Such comparisons have for years been a major obsession of materials scientists who use computer simulation because the acceptance of the simulation approach depends entirely on confidence in its validity. For example, CALPHAD, or the calculation of binary or ternary phase diagrams from thermochemical measurements used as input, is one form of computer simulation dating back to the early 1960 s. For most of the intervening years, its practitioners have compared CALPHAD predictions with experimentally determined phase diagrams. At last, today, customers are mostly prepared to accept the validity of such predictions even without immediate experimental backup. Confidence is all.
One central advantage of computer simulation is that it can be used like a spreadsheet in finance or industrial management. If a model for, say, grain-boundary properties or anomalously fast diffusion depends on numerous variables, any one of these variables can be changed and the consequent change of predicted structure, or properties, can be very rapidly computed. This kind of one-thing-at-a-time change in a computer simulation is intellectually akin to combinatorial chemistry, as practiced originally in pharmacology (drug development) and now also in the improvement of (functional) electronic materials where the effects of numerous small compositional variations are rapidly tested in an automated experimental setup. In my view, this "spreadsheet" aspect of computer simulation justifies regarding the technique as a form of quasiexperiment; I believe it is more productive to regard simulation in this way rather than as a second-class (non-analytical) form of theory.

One central advantage of
computer simulation is that it
can be used like a spreadsheet
in finance or industrial
management.

Early in the development of computers, a senior executive of IBM opined that half a dozen or so large installations would saturate the market; this was akin to some early prophecies by military experts, for instance, about the certain uselessness of air power. Computers are effectively used today in many different ways to perform a variety of tasks. First, many forms of processes, such as plastic deformation, sintering, and polymer extrusion, have been simulated and thereby improved in detail. This use is likely to continue to grow. A particularly fruitful approach is to predict properties of polymers as a function not only of chemical composition and molecular weight, but also of "mesoscopic" or medium-range structure, that is, the shapes of the long-chain molecules and statistical models of their interaction. This represents a prime example of the "spreadsheet" approach. The study of interface structure and properties is another interesting example.

Computer simulation is on the way to becoming the prime exemplar of a parepisteme, and I predict that as confidence in its methodology grows, so its role (relative to traditional theory and experiment) will steadily expand.
In this essay I have steered clear of discussion of new materials in terms of categories. Recent popular texts on materials have focused on functional materials of various kinds at the expense of structural materials, and this change of emphasis has led to errors in historical understanding, such as the fantasy that the steel industry is a "smokestack" domain devoid of any serious modern science. As with all swings of the pendulum, this one will repair itself in due time.

Some of the giants who drove materials science forward in past years have been mentioned. That is not to say that the era of great materials scientists has passed. In fact, to quote a chair's remark retailed by a science historian, Gerald Holton, "Today we are privileged to sit side-by-side with the giants on whose shoulders we stand."

The whole raison d'etre of materials science is to achieve cross-fertilization between understanding of different categories of materials. This is at last beginning to become explicit in materials science education: A very recent undergraduate textbook by S.M. Allen and E.L. Thomas of Massachusetts Institute of Technology, Structure of Materials (Wiley \& Sons, New York, 1999), is predicated on this approach. It is even gradually becoming possible to integrate the study of polymers, hitherto resistant to such integration, with the rest of MSE; such concepts as phase diagrams, dislocation motion, and crystal perfection are making their appearance in some polymer research. I hope and believe that this kind of integration will become more and more widespread in the years to come.

\section{Suggested Readings}

1. R.W. Cahn, Physics of Materials, chapter in Twentieth Century Physics, edited by L.M. Brown, A. Pais, and B. Pippard (Institute of Physics Publishing, Bristol, UK, and American Institute of Physics Press, New York, 1995), p. 1505.

2. E. Braun, Mechanical Properties of Solids, and S.R. Weart, The Solid Community, chapters in Out of the Crystal Maze, edited by L. Hoddeson, E. Braun, J. Teichmann, and S. Weart (Oxford University Press, New York, 1992), pp. 317, 617. 3. N. Mott, ed., The Beginnings of Solid State Physics, a special issue of Proc. Roy. Soc. (London) 371 (1980) pp. 1-177.

4. D. Raabe, Computational Materials Science (Wiley-VCH, Weinheim, 1998).

5. D. Frenkel and B. Smit, Understanding Molecular Simulation (Academic Press, San Diego, 1996).

6. N. Saunders and A.P. Miodownik, CALPHAD-Calculation of Phase Diagrams, A Comprehensive Guide (Pergamon, Oxford, 1998). 7. P. Ball, Made to Measure: New Materials for the 21st Century (Princeton University Press, Princeton, 1997).

Robert W. Cahn was trained at Cambridge University as a physical metallurgist and all 
his personal research has been in this field. From 1965 to 1981 he held the first chair in Britain, at Sussex University, designated in materials science and there he helped to define the nature of the nascent discipline, in part by becoming founder-editor in 1966 of a new periodical, Journal of Materials Science. Before that, he was founder-editor of the Journal of Nuclear Materials; later, in 1985-1992, he helped develop MRS's Journal of Materials
Research, and since 1993 he has been co-editor of a new journal, Intermetallics. $\mathrm{He}$ is now attached, in nominal retirement, to his alma mater, Cambridge. Since 1967, he has written approximately 100 articles of scientific popularization in materials science for the weekly journal Nature. He was joint editor-in-chief of a series of 18 multi-author volumes (1991-1999) encompassing most of materials science and technology, and has been editorial- ly involved with three materials encyclopedias, one of these now in preparation. He has been editor of two successive monograph series in materials science, first for Cambridge University Press and now for Elsevier Science Ltd. Cahn is currently writing a historical book, The Coming of Materials Science, which will appear next year in the Pergamon Materials Series, published by Elsevier. Cahn is a Fellow of the Royal Society of London.

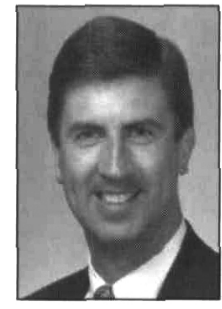

\section{Bravman to Lead Undergraduate Education at Stanford University} John C. Bravman, the chair of the Department of Materials Science and Engineering and the Bing Centennial Professor at Stanford University and 1994 president of the Materials Research Society, has been named vice provost for undergraduate education. Bravman's appointment became effective September 1 .

"I'm thrilled and honored to take on the important task of ensuring that Stanford's unparalleled efforts at the undergraduate level continue to move forward," Bravman said.

Provost John Hennessy said that Bravman "brings a real wealth of experience as well as a passion for working for students that I think is truly extraordinary."

While the Stanford Introductory Studies (SIS) developed during the term of the previous vice provost has concentrated on the first two years of the undergraduate experience, Bravman will look toward enhancing the major programs as well as making possible changes in the Science, Mathematics, and Engineering Core, which is an option for nonscience majors in fulfilling the undergraduate general education requirements.

Bravman also will be involved with developing a solid financial basis to sustain the recent improvements in undergraduate offerings at Stanford. He especially will be seeking funds to endow undergraduate research initiatives. "I think perhaps as many as a third of undergraduates are looking for a substantial research experience either over the summer or during the year or both," he said.

Bravman, who will serve a five-year term, will continue as senior associate dean for student affairs in the School of
Engineering. He will also continue to conduct research with his group of PhD students. His research focuses on the mechanical behavior of thin film materials and the reliability of the microscopic structures found in computer chips and other microelectronic circuitry. His group has pioneered techniques for imaging and tracking the movements of the microscopic voids that appear in the metal contact lines used in such circuits. The group also is developing methods to test and analyze the fatigue and fractures that develop in thin films. Such methods are needed to identify highly reliable films that can be used in the construction of devices that combine microscopic electronic circuitry and microscopic mechanical components.

After receiving his $\mathrm{BS}, \mathrm{MS}$, and $\mathrm{PhD}$ degrees in materials science and engineering at Stanford, Bravman was named assistant professor in the department in 1985, achieving full professorship in 1995.

Among other honors, he received the Walter J. Gores Award for Excellence in Teaching in 1989. He also has served as a resident fellow and on a wide variety of committees and boards, including the Commission on Undergraduate Education.

\section{Copper-Indium-Gallium- Diselenide Semiconductor Heals Itself}

An international team consisting of David Cahen of the Weizmann Institute's Materials and Interfaces Department, working with consultant Leeor Kronik of Tel Aviv University and colleagues from France's CNRS and Germany's Stuttgart University have discovered a self-healing process that can occur in a copper-indiumgallium-diselenide semiconductor. This finding, presented in June at the European Materials Research Conference in Strasbourg and scheduled for publication in Advanced Materials, may help create better solar cells and other electronic devices.
Their discovery is based, among other things, on a study in which crystals of a related material, copper indium diselenide, were examined using high-energy $x$-rays. In that study, conducted by Cahen and other colleagues at the European Synchrotron Research Facility in Grenoble, it was shown that in some cases the bonds between certain atoms of copper indium diselenide can be broken relatively easily.

Cahen's group had also shown that copper atoms can move inside these semiconductor crystals. He said that this finding was surprising because such movement is uncommon in solid, nonliving materials, and extremely unusual in materials used in electronic devices where atomic mobility is viewed as anathema. Moreover, he said, seeing it in a semiconductor known for its stability was particularly unexpected.

The researchers furthermore found that once some atomic bonds have been broken, the copper atoms, which are capable of moving throughout the crystal, wander around until they reach the damaged spot and undo the effects of the damage. This "self-repair" mechanism stems from the material's tendency to try and stay close to equilibrium.

Cahen said, "Now we understand how solar cells made of copper indium gallium diselenide manage to survive and function effectively in hostile environments such as those encountered on satellites: Once damaged, for example by radiation, this 'smart' material simply 'heals' itself and restores its previous function."

\section{Microwave-Sintered Metal Parts Demonstrate Finer Grain Size than Conventional Sintering}

A team of materials scientists at The Pennsylvania State University is microwaving a wide range of powder metals and producing machine components with improved properties over those produced through traditional sintering methods. 